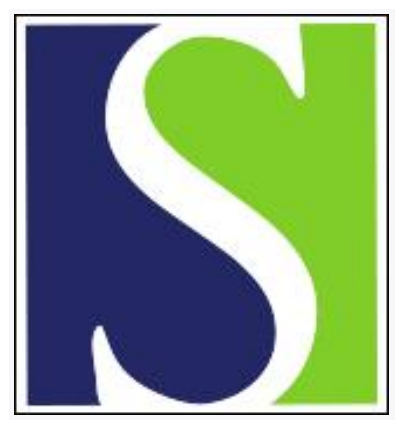

Scand J Work Environ Health 2009;35(5):376-383

https://doi.org/10.5271/sjweh.1347

Published online: 25 Aug 2009, Issue date: 00 Oct 2009

Evaluation of respiratory effects related to high-pressure cleaning in a piggery with and without robot pre-cleaning by Hiel D, von Schéele I, Sundblad B-M, Larsson K, Palmberg L

Affiliation: Lung and Allergy Research, Institute of Environmental Medicine, Karolinska Institutet, PO Box 287, SE-171 77 Stockholm, Sweden. lena.palmberg@ki.se

Refers to the following texts of the Journal: 2006;32(2):145-153 2002;28(4):256-263

Key terms: airway inflammation; cleaning; evaluation; high-pressure cleaning; organic dust; piggery; pre-cleaning; respiratory effect; robot; robot pre-cleaning

This article in PubMed: www.ncbi.nlm.nih.gov/pubmed/19705041 


\title{
Evaluation of respiratory effects related to high-pressure cleaning in a piggery with and without robot pre-cleaning \\ by Deline Hiel, MSc, ${ }^{1}$ Ida von Schéele, MSc, ${ }^{1}$ Britt-Marie Sundblad, PhD, ${ }^{1}$ Kjell Larsson, MD, PhD, ${ }^{1}$ Lena Palmberg, $M D, P h D^{1}$
}

\begin{abstract}
Hiel D, von Schéele I, Sundblad B-M, Larsson K, Palmberg L. Evaluation of respiratory effects related to high-pressure cleaning in a piggery with and without robot pre-cleaning. Scand $J$ Work Environ Health. 2009;35(5);376-383.
\end{abstract}

Objective Exposure in connection with cleaning piggeries induces airway inflammation. The aim of this study was to compare the health effects related to two different pre-cleaning processes in a piggery.

Methods In a cross-over study design, 12 subjects were randomly exposed for three hours during the cleaning of a piggery with a high pressure water jet, with and without pre-cleaning using a robot. We assessed lung function, bronchial responsiveness, symptoms, body temperature, and exhaled nitric oxide, and performed blood sampling and nasal lavage before and after both exposures.

Results Compared with ordinary cleaning without the use of a robot, pre-cleaning with a robot significantly reduced the increase in bronchial responsiveness $(\mathrm{P}=0.049)$, total cell number $(\mathrm{P}=0.0029)$, and pro-inflammatory cytokines (IL-8 level $[\mathrm{P}=0.016])$ in nasal lavage, and diminished the increase in neutrophils $(\mathrm{P}=0.0029)$ in the blood.

Conclusion Pre-cleaning of a piggery with a robot reduced exposure to dust and endotoxin, and resulted in an attenuation of the increase in bronchial responsiveness and the airway inflammatory response compared precleaning without a robot.

Key terms robot; organic dust; airway inflammation.

People working in the pig farming industry have an increased prevalence of respiratory symptoms and diseases such as chronic bronchitis and chronic obstructive pulmonary disease (1-4). Exposure of healthy, previously unexposed volunteers in the farming environment has resulted in intense airway inflammation and increased bronchial responsiveness. The exposureinduced airway inflammation in volunteers is characterized by a multifold increase of inflammatory cells (mainly neutrophilic granulocytes), pro-inflammatory cytokines (IL-6 and IL-8) in blood, nasal, and bronchoalveolar lavage fluid, and increased levels of exhaled nitric oxide (NO) (5-7). The reaction in both farmers and volunteers is most likely caused by the high levels of airborne organic dust in the piggery (8).

Larsson et al has shown that the cleaning of the interior of the stable is a working situation that causes a high dust exposure with a greater proportion of respirable dust compared with exposure when weighing pigs (9). After each completed breeding period, the stables are normally soaked with sprinklers during the night and subsequently manually cleaned using a high-pressure water jet. The high proportion of respirable dust measured during this cleaning procedure could originate from the fragmentation of dust particles by the highpressure cleaner's water jet that, together with dampness in the stable, intensifies the exposure as previously shown. Even though the exposure to dust was approximately 20 times lower during the cleaning of the stable compared to when weighing pigs, the post-exposure increase in bronchial responsiveness is similar on both occasions. It has also been shown that wearing a mask attenuated, but did not abolish, the effects of exposure in healthy volunteers (9-11).

Recently, an automatic cleaning robot (Ramsta Robotics, Uppsala, Sweden) has come into use in piggeries. The robot pre-cleans the stables during the night and the farmer finishes the cleaning procedure with a water jet on the subsequent day. This procedure lowers the exposure time for the farmer up to $75 \%(12-13)$. The robot

1 Lung and Allergy Research, Institute of Environmental Medicine, Karolinska Institutet, Stockholm, Sweden.

Corresponence to: Dr L Palmberg, Lung and Allergy Research, Institute of Environmental Medicine, Karolinska Institutet, PO Box 287, SE-171 77 Stockholm, Sweden. [E-mail: lena.palmberg@ki.se] 
is, however, expensive and has to be specially adjusted for each stable by an expert, which is a time-consuming procedure. It is unknown whether the use of the robot influences the health impact of the cleaning procedure on the farmer. Even though the dust exposure and exposure time is reduced when using the robot, the higher proportion of the respirable dust fraction might indicate a deeper penetration of small particles into the lungs, which in turn may cause more severe health effects.

Using a cross-over design, the aim of this study was to evaluate the acute effect of the cleaning processes, with and without pre-cleaning using a robot, on previously unexposed volunteers.

\section{Materials and methods}

\section{Subjects}

Twelve healthy, non-smoking volunteers participated in the study [nine women, mean age 27 (range 20-37) years]. The participants had no respiratory symptoms or diseases, and no allergies as confirmed by a questionnaire and skin prick tests using 17 common aeroallergens. Other inclusion criteria included normal results of a physical examination, spirometry, and bronchial responsiveness to methacholine. None of the volunteers had previously been exposed to farm dust. All volunteers gave their informed consent. The study was approved by the ethics committee at the Karolinska Institutet (2005/1163-31/4).

\section{Study design}

The subjects were twice exposed for three hours in a piggery for both exposure settings. During the exposure, the farmer was cleaning the stable with a high-pressure cleaner. On one occasion, the cleaning robot had carried out an automatic cleaning on the previous day. On the other occasion, cleaning was preceded by soaking the stables with a sprinkler installation (ie, no robot was used). The study was performed in a randomized, crossover design, with a wash-out period of at least one month between the two exposures. Six persons were exposed on each occasion, resulting in two exposures of pre-cleaning with a robot and two exposures of pre-cleaning without a robot. During each exposure, 2-3 of the volunteers wore personal samplers for exposure monitoring. Two weeks prior to the exposure, all subjects underwent spirometry, bronchial methacholine provocation, and nasal lavage and blood sampling; exhaled nitric oxide (NO) was also measured. The same tests were repeated seven hours after the start of each exposure. Immediately prior to and after exposure, we measured peak expiratory flow (PEF), symptoms, and oral temperature.

\section{Exposure measurements}

Inhalable dust (IOM filter cassettes $25 \mathrm{~mm}$, SKC Ltd, Dorset, United Kingdom) and respirable dust (plastic cyclones $[25 \mathrm{~mm}$, Casella Ltd, London, United Kingdom]) were sampled in the breathing zone with portable pumps with an airflow of 1.9-2 1/min. The cassettes were equipped with Teflon filters (1.0, Millipore, Sundbyberg, Sweden). We performed at least two measurements of both inhalable and respirable dust during each exposure.

After weighing, we extracted the filters and analyzed them for endotoxins using a kinetic technique version of limulus amebocyte lysate (LAL) assay (Endosafe Endochrome-K, Coatech AB, Kungsbacka, Sweden) with E. coli 0.111:B4 as standard (14). To ensure that $\beta$-glucans, which are most likely present in the dust, did not interfere with the assay, we used an endotoxinspecific buffer (Charles River Endosafe, Charleston, USA) to dilute the LAL assay according to manufacturer recommendations.

For all duplicates, an intra-assay variation of $<15 \%$ was accepted. The detection limit for endotoxins was $0.02 \mathrm{EU} / \mathrm{ml}$ corresponding to $40 \mathrm{ng} / \mathrm{m}^{3}$.

\section{Symptoms}

We assessed general and airway specific symptoms using a $100 \mathrm{~mm}$ visual analogue scale. The volunteers were requested to put a cross on the scale where 0 indicated "no symptoms" and 100 indicated "unbearable symptoms". We measured oral temperature directly before exposure and then every hour up to eight hours after the start of exposure.

\section{Lung function and bronchial responsiveness}

We measured vital capacity and forced expiratory volume in one second $\left(\mathrm{FEV}_{1}\right)$ using a wedge spirometer (Vitalograph ${ }^{\circledR}$, Buckingham, United Kingdom) according to the criteria of the American Thoracic Society (15). Local reference values were used (16-17). We measured PEF immediately prior to and after exposure and every hour up to five hours following exposure with a miniWright peak flow meter (Clement Clarke Ltd, London, United Kingdom). We registered the best out of three measurements.

Bronchial responsiveness to methacholine was measured as has been previously described (18). The results were expressed as the cumulative dose causing a $20 \%$ decrease in $\mathrm{FEV}_{1}\left(\mathrm{PD}_{20} \mathrm{FEV}_{1}\right)$. The dose/response slope of change in $\mathrm{FEV}_{1}$ was calculated by linear regression including all data points, as the percent change of $\mathrm{FEV}_{1}$ as a function of the cumulated methacholine dose (19). 


\section{Exhaled nitric oxide}

We measured NO in exhaled air using a single-breath exhalation with $50 \mathrm{ml} / \mathrm{s}$ flow rate, according to the American Thoracic Society recommendations (20). The analysis was conducted after reaction with ozone (NIOX®), Aerocrine, Stockholm, Sweden) as described earlier (11). To decrease contamination from the oral cavity, preceding the measurement, the mouth was rinsed with water and a sodium bicarbonate solution (10\%) for 30 seconds each (21).

\section{Nasal lavage}

Nasal lavage was performed using a procedure described by Bascom et al, with minor modifications (22). The lavage samples were centrifuged, and the numbers of cells were counted in a Bürker chamber. The supernatant was frozen before analyses. IL-6 and IL-8 were determined in the samples using an enzyme-linked immunosorbent assay developed at our laboratory using commercially available antibody pairs (R\&D Systems Ltd, Europe, Abingdon, United Kingdom) (23). The lower detection limit of IL-6 and IL-8 were $3 \mathrm{pg} / \mathrm{ml}$ and $50 \mathrm{pg} / \mathrm{ml}$, respectively. For duplicated samples, we accepted an intra-assay coefficient of variation of $<10 \%$ and an inter-assay coefficient of variation of $<20 \%$.

\section{Blood leukocyte analysis}

Whole peripheral blood was collected in ethylene diaminetetra-acetic acid vacutainer tubes (BD Bioscience, New Jersey, USA) and tested within two hours of the sampling.
The samples were analyzed in Attractors ${ }^{\mathrm{TM}}$ (BD Bioscience, San Jose, CA, USA) to perform a five-part white blood cell differential, as previously described (11).

\section{Statistics}

Lung function, symptoms, and cell distribution in blood are presented as means and $95 \%$ confidence intervals $(95 \%$ CI). Statistical comparisons between the exposures were assessed by analysis of variance (repeated measures) followed by the Student's t-test for paired observations as a post hoc test when appropriate. For not normally distributed data, the results are presented as medians and $25^{\text {th }}-75^{\text {th }}$ percentile (exhaled nitric oxide, bronchial responsiveness, and nasal lavage fluid results). Statistical comparisons between exposures were then assessed by the Friedman test followed by the Wilcoxon signed rank test when appropriate or by the Spearman rank correlation test. We considered a P-value of $<0.05$ significant.

\section{Results}

\section{Exposure measurements}

Significantly lower levels of inhalable dust $(\mathrm{P}=0.023)$ were observed when the stable was pre-cleaned with the robot, whereas respirable dust levels were similar for both exposures (figure 1). Endotoxin levels in inhalable $(\mathrm{P}=0.0062)$ and respirable dust $(\mathrm{P}=0.014)$ were also lower when the stable was pre-cleaned with the robot.
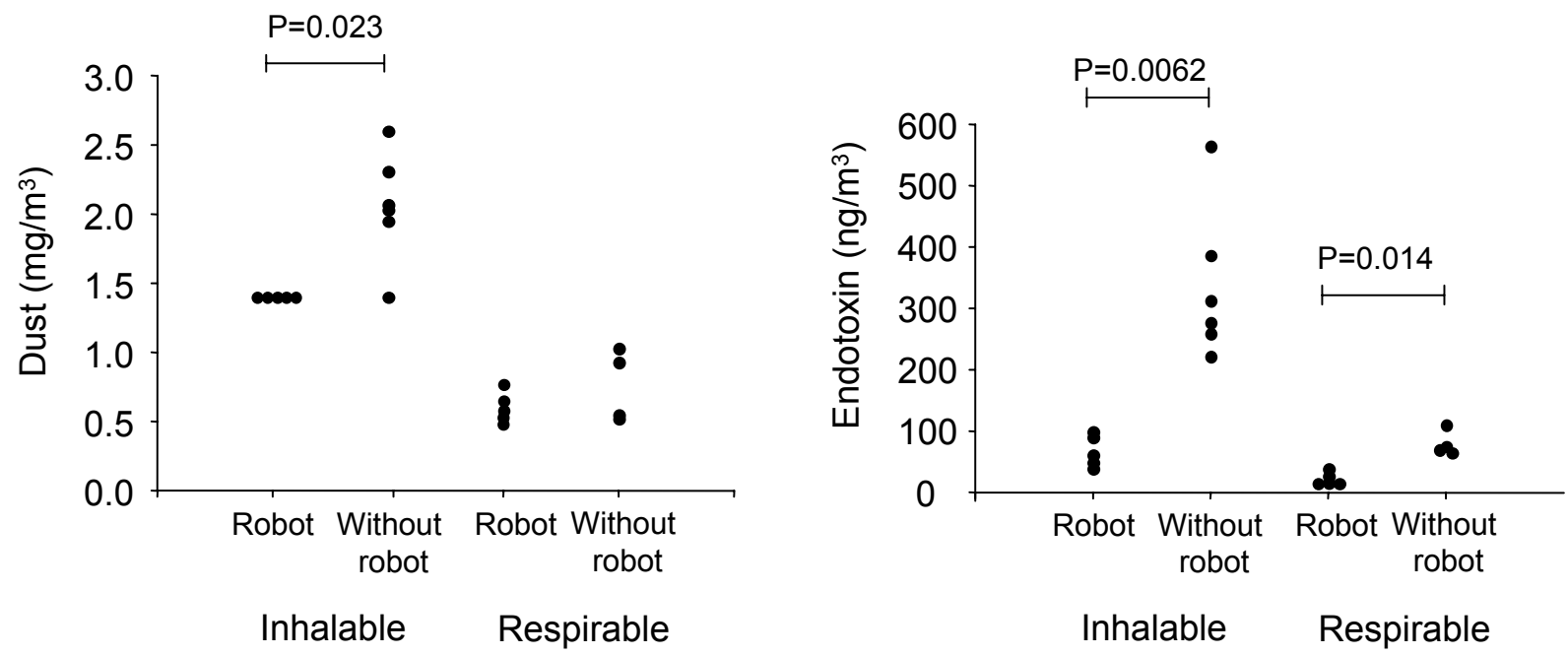

Figure 1. Inhalable and respirable dust and endotoxin levels for both exposures after robot cleaning and without the use of a robot. Detection limits were $1.4 \mathrm{mg} / \mathrm{m}^{3}$ and $0.3 \mathrm{mg} / \mathrm{m}^{3}$ for inhalable and respirable dust, respectively and $40 \mathrm{ng} / \mathrm{m}^{3}$ for endotoxin exposure. Each value is based on 4-6 measurements. 


\section{Symptoms}

Chills were reported after both exposures $(\mathrm{P} \leq 0.017)$, with no difference between the two $(\mathrm{P}=0.145)$. Chest tightness $(\mathrm{P}=0.032)$ and cough $(\mathrm{P}=0.001)$ were significant only after exposure without robot pre-cleaning, with no significant differences between the exposures. Body temperature increased $0.9^{\circ} \mathrm{C}(95 \%$ CI $0.45-1.45)$ when exposed after robot pre-cleaning and $0.8^{\circ} \mathrm{C}(95 \%$ CI 0.6-1.3) when the robot was not used.

\section{Lung function and bronchial responsiveness}

Pre-exposure lung function of vital capacity and $\mathrm{FEV}_{1}$ were normal for all participants. Pre-exposure percentage of predicted value for vital capacity was mean $97 \%$ (95\% CI 90-103), and for $\mathrm{FEV}_{1}$ mean 98\% (95\% CI 91-105), respectively. Both exposures caused a significant decrease in PEF $(\mathrm{P}<0.01)$, but not in other lung function parameters (table 1). No significant difference between the two exposures was found.

The $\mathrm{PD}_{20} \mathrm{FEV}_{1}$ decreased significantly only after the exposure without robot pre-cleaning $(\mathrm{P}=0.034)$, with no significant difference between the two exposure days (table 1). The dose response slope increased significantly only without robot pre-cleaning ( $\mathrm{P}=0.0076)$, and significantly more than when the robot was used $(\mathrm{P}=0.049)$.

\section{Exhaled nitric oxide}

The level of exhaled NO increased without the use of a robot although not significantly, but significantly more than when pre-cleaning with a robot $(\mathrm{P}=0.0049)$.

\section{Nasal lavage}

After pre-cleaning the stable with the robot, the number of inflammatory cells in nasal lavage fluid doubled $(\mathrm{P}=0.022)$ (figure 2); without the use of a robot, a more than five-fold increase was observed $(\mathrm{P}=0.0022$; $\mathrm{P}=0.0029$ between exposures). No significant differences were found in the concentrations of IL- 6 before and after the two exposures $(\mathrm{P}=0.30)$. The concentration of IL-8 increased following exposure without robot precleaning $(\mathrm{P}=0.0033)$ and significantly more than after pre-cleaning with a robot $(\mathrm{P}=0.016)$. There was a significant correlation between IL-8 concentrations and the cell number in nasal lavage fluid (Rho=0.58; $\mathrm{P}=0.0006$ ).

\section{Blood leukocyte analysis}

The total number of leukocytes in peripheral blood increased significantly after both exposures $(\mathrm{P} \leq 0.020)$, but significantly less using the robot $(\mathrm{P}<0.001)$. The change was mainly due to a greater increase in neutrophilic granulocytes which was significantly higher when not using the robot compared with robot pre-cleaning $(\mathrm{P}=0.003)$ (figure 3$)$. The number of monocytes, and $\mathrm{T}$ helper cells increased significantly after both exposures. The increase in monocytes were higher after exposure without using the robot $(\mathrm{P}<0.0002)$, but no significant difference in blood T-helper cells was found between the two exposures.

Table 1. Results of the measurements of lung function and exhaled nitric oxide (NO). Pre-exposure values were $>80 \%$ of predicted in all participants (within $80-120 \%$ of predicted value). Peak Expiratory Flow (PEF) fell significantly following exposure, with no significant difference between the two exposures. Bronchial responsiveness to methacholine are presented as $\mathrm{PD}_{20} \mathrm{FEV}_{1}$ (ie, the cumulative dose) causing a $20 \%$ fall in $\mathrm{FEV}_{1}$ (forced expiratory volume in 1 second) or the dose/response slope (DRS) of change in FEV 1 . Data which had a $\mathrm{P}>0.05$ are considered not significant and not listed in the footnotes. (IR = interquartile range, $V \mathrm{C}=$ vital capacity)

\begin{tabular}{|c|c|c|c|c|c|c|c|c|c|c|c|c|c|c|c|c|}
\hline & \multicolumn{2}{|r|}{ VC (I) } & \multicolumn{2}{|r|}{$\mathrm{FEV}_{1}(\mathrm{I})$} & \multicolumn{2}{|c|}{$\mathrm{FEV}_{1} \mathrm{NC}$} & \multicolumn{4}{|c|}{$\operatorname{PEF}(1 / \mathrm{min})^{\text {a }}$} & \multicolumn{2}{|c|}{$\mathrm{PD}_{20} \mathrm{FEV}_{1}(\mathrm{mg})$} & \multicolumn{2}{|c|}{$\operatorname{DRS}\left(\% / \mathrm{mg}^{-1}\right)$} & \multicolumn{2}{|c|}{ NO (ppb) } \\
\hline & Mean & $95 \% \mathrm{Cl}$ & Mean & $95 \% \mathrm{Cl}$ & Mean & $95 \% \mathrm{Cl}$ & Mean & n $95 \% \mathrm{Cl}$ & Mean & $95 \% \mathrm{Cl}$ & Median & $\mathrm{IR}$ & Median & $\mathrm{IR}$ & Median & $\mathrm{IR}$ \\
\hline Pre-exposure & 4.49 & $3.79-5.18$ & 3.79 & $3.23-4.35$ & 84 & $81-87$ & 538 & 470-605 & 525 & $450-600$ & 1.7 & $0.5-14.4$ & 16.3 & $1.3-42.3$ & 9.7 & $7.8-17.4$ \\
\hline \multicolumn{17}{|l|}{ After exposure } \\
\hline With robot & 4.44 & $3.76-5.12$ & 3.78 & 3.24-4.31 & 84 & $82-87$ & $515^{\mathrm{b}}$ & $447-582$ & .. & .. & 0.8 & $0.4-4.1$ & 24.9 & $4.1-66.2$ & 9.9 & $7.4-14.3$ \\
\hline Without robot & 4.43 & $3.79-5.08$ & 3.78 & $3.26-4.31$ & 85 & $82-87$ &.. & .. & $502^{\circ}$ & $434-569$ & $0.2^{d}$ & $0.1-1.3$ & $91.5^{\mathrm{c}} 1$ & $9.6-151.7$ & 13.2 & $10.8-22.3$ \\
\hline
\end{tabular}

Between exposure

P-value

0.049

0.0047

a There are two sets of PEF (I/min) values because this was measured on each exposure day and not on the day two weeks prior to the exposure as other pre-exposure values.

b Comparisons with pre-exposure value, $\mathrm{P}<0.001$.

${ }^{c}$ Comparisons with pre-exposure value, $\mathrm{P}<0.01$

d Comparisons with pre-exposure value, $\mathrm{P}<0.05$. 

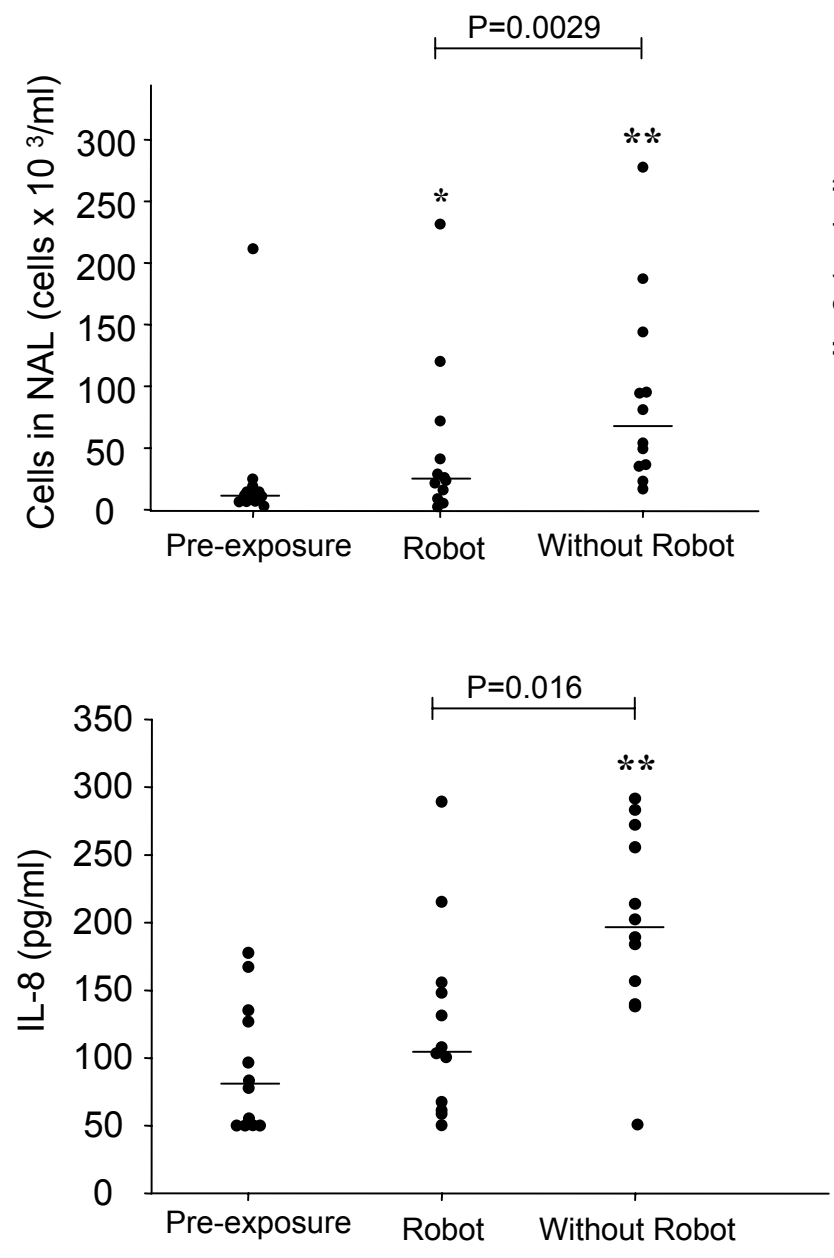

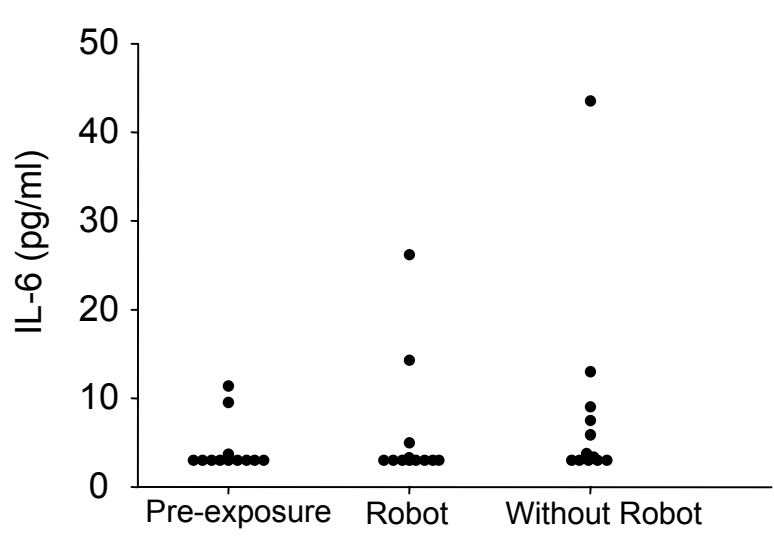

Figure 2. Total cell number, IL-6, and IL-8 in nasal lavage fluid (NAL). Individual values before and after the two exposures are shown, with median values indicated as horizontal lines. ${ }^{*} P<0.05$, ${ }^{*}{ }^{*} \mathrm{P}<0.01$ compared to pre-exposure values. Significant differences between the exposures are indicated in the figures.

\section{Discussion}

Manual cleaning of a piggery inevitably results in exposure to airborn material. In this study, it has been demonstrated that pre-cleaning with a robot reduces the inflammatory reaction compared to soaking the stable over night with a sprinkler (ie, pre-cleaning without the use of a robot). Pre-cleaning the stable with a robot yielded reduced inhalable dust levels and lowered endotoxin levels in inhalable and respirable dust. The use of a robot also significantly reduced the increase in bronchial responsiveness, the inflammatory response in the nose, and the systemic reaction that was assessed as increase of circulating neutrophils and monocytes

Cleaning of the interior of the stable after a completed breeding period induced an inflammatory reaction in the respiratory tract as shown in this and a previous study (9). The magnitude of increase in bronchial responsiveness was similar to that which has been found in subjects exposed during the weighing of pigs $(7,8$, $10,11,23)$. This was a somewhat surprising finding considering that the exposure to inhalable dust was reduced up to 20 times during the cleaning procedure. However, the respirable fraction including endotoxin content, which consequently can penetrate into the lower airways, was on the other hand of the same magnitude as, or even higher than, during the weighing of pigs (24-25). These findings suggest that the water jet can break the particles into smaller pieces.

Apart from a reduction of PEF, no changes in lung function (vital capacity and $\mathrm{FEV}_{1}$ ) could be detected after exposure compared to pre-exposure values, in agreement with a previous study (9). The apparent discrepancy between the findings of a significant decrease in PEF, but not $\mathrm{FEV}_{1}$ could be due to the time of the measurement. Since PEF was measured hourly throughout the day and $\mathrm{FEV}_{1}$ was only measured seven hours after exposure, it is possible that lung function was already normalized at the time of $\mathrm{FEV}_{1}$ measurements.

The level of NO in exhaled air did not increase significantly after either exposure, although a significant difference between the exposures was found. The lack of a significant increase after cleaning without the use 

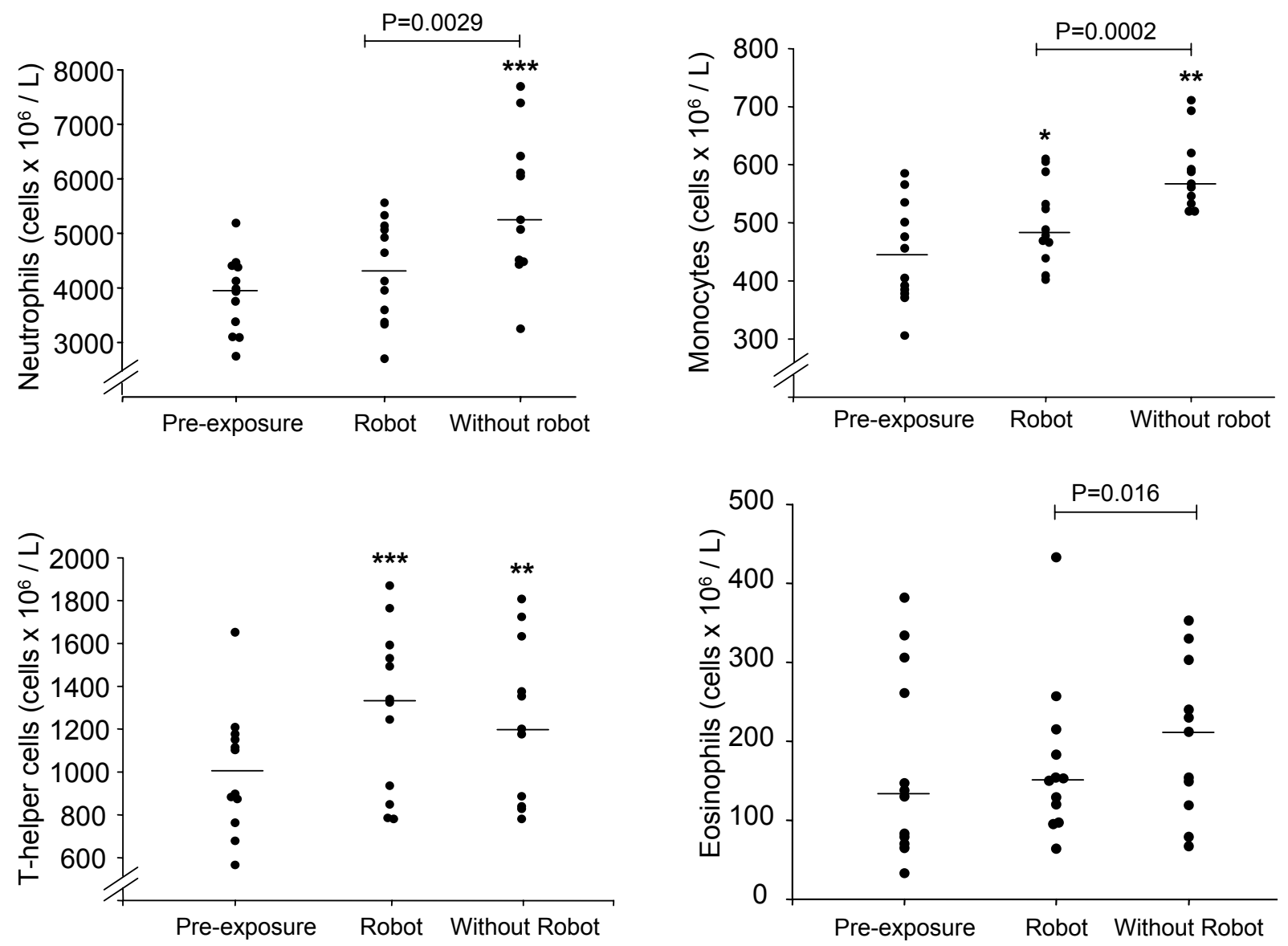

Figure 3. Total numbers of neutrophils, monocytes, T-helper cells, and eosinophils in blood before and after both exposures. Individual values before and after the two exposures are shown, with median values indicated as horizontal lines. ${ }^{*} \mathrm{P}<0.05,{ }^{* *} \mathrm{P}<0.01$ compared to pre-exposure values. Significant differences between the exposures are indicated in the figures.

of robot is probably due to the variation in pre-exposure values. The robot apparently attenuated the effect of cleaning on exhaled NO. As NO is considered to be a biomarker for lower airway inflammation, the use of a robot thus seems to attenuate the pro-inflammatory effect of exposure.

When the stable was not pre-cleaned using the robot, we found a significant decrease in $\mathrm{PD}_{20} \mathrm{FEV}_{1}$ and an increase in the slope compared to pre-exposure values. However, only the slope increased significantly more when not using a robot compared to pre-cleaning with a robot. It thus seems as if pre-cleaning with the robot leads to a smaller increase in bronchial responsiveness although this could only be demonstrated for one parameter due to the small sample.

A previous study has shown that lipopolysaccharide (LPS) most likely is not the major cause of the increase in bronchial responsiveness, following exposure in a pig barn (14). That study found that bronchial responsiveness in farmers, smokers, and control subjects increased more after exposure in a piggery while weighing pigs, compared to a pure LPS-provocation. The concentration of LPS was 15 times higher during the LPS-provocation than the concentration of endotoxin in the respirable dust while weighing pigs. It has also been shown that mice with defective TLR4 (a toll-like receptor for LPS) have an attenuated inflammatory response in the lung, but there was no effect on bronchial responsiveness after exposure in a piggery compared to wild-type (WT) mice (26). The low impact of LPS as a causative agent of increased bronchial responsiveness is also supported by Sundblad et al who showed that, despite wearing a respirator with filters protective for both particles and gas which reduced endotoxin exposure by $99 \%$, an increase in bronchial responsiveness could still be observed (11). Ultra fine particles, uptake through the skin, and exposure to organic dust prior to entering the piggery may contribute to the increased bronchial responsiveness. These results indicate that LPS is not the sole cause of the increased bronchial responsiveness following exposure in a pig house $(11,14,26)$.

The results of our study showed that the use of 
a cleaning robot reduced the increase in bronchial responsiveness apparently by decreasing the exposure to agents that cause such an increase. The study's crossover design could have made this possible in contrast to previous comparative studies that included two parallel groups. This study design was chosen as a consequence of the study by Strandberg et al where it was proven that the final post-exposure bronchial responsiveness is independent of pre-exposure values (25).

This study has shown that the use of a robot reduced the inflammatory reaction after three hours of exposure during cleaning procedures in healthy, unexposed volunteers. Differences between the two exposures was observed for systemic parameters in peripheral blood as well as inflammatory parameters in both lower (exhaled NO, bronchial responsiveness) and upper (nasal lavage) airways. It is, however, still unknown if chronically exposed farmers will react in the same way as unexposed volunteers.

In addition to the reduced inflammatory response observed following exposure after pre-cleaning with the robot, it should be considered that the use of the robot also lowers the duration of exposure for the farmer by approximately $75 \%$, a fact that might be even more important in health aspects (12-13). The stable must be cleaned after each breeding period and is normally a working task which results in high exposure to organic dust. The dampness of the stables, which makes it difficult for the farmers to protect themselves with respirators, the continuous duration of exposure (up to two days), and the high proportion of respirable dust due to the use of a high-pressure water jet, indicate that piggery cleaning is a major work environment problem that needs to be improved. The possibility of using a robot during the cleaning process, which both reduces the duration and biological effects of the exposure, might, in the long run, improve the work environment for pig farmers.

\section{Acknowledgements}

This study was supported by grants from the Swedish Farmer Foundation for Agricultural Research, the Swedish Heart and Lung Foundation, and Karolinska Institutet. We thank Karin Sahlander, Alexandra Ek and Marianne Olsson, at the Institute of Environmental Medicine, Karolinska Institutet, for their excellent technical assistance. We also thank Dr Karin Strandberg for the physical examination of the volunteers. The study was done in collaboration with Anna Torén, Clas Jonsson, and Niklas Adolfsson at the Swedish Institute of Agricultural and Environmental Engineering. We would also like to thank the owners of Upppig who gave us the opportunity to perform the study at their piggery.

\section{References}

1. Larsson K, Eklund A, Malmberg P, Belin L. Alterations in bronchoalveolar lavage fluid but not in lung function and bronchial responsiveness in swine confinement workers. Chest. 1992;101:767-74.

2. Vogelzang PF, van der Gulden JW, Tielen MJ, Folgering H, van Schayck CP. Health-based selection for asthma, but not for chronic bronchitis, in pig farmers: an evidence-based hypothesis. Eur Respir J. 1999;13:187-9.

3. Zejda JE, Hurst TS, Rhodes CS, Barber E, McDuffie HH, Dosman JA. Respiratory health of swine producers: focus on young workers. Chest. 1993;103:702-9.

4. Monso E, Riu E, Radon K, Magarolas R, Danuser B, Iversen $\mathrm{M}$, et al. Chronic obstructive pulmonary disease in never-smoking animal farmers working inside confinement buildings. Am J Ind Med. 2004;46:357-62.

5. Larsson BM, Palmberg L, Malmberg PO, Larsson K. Effect of exposure to swine dust on levels of IL-8 in airway lavage fluid. Thorax. 1997;52:638-42.

6. Wang Z, Larsson K, Palmberg L, Malmberg P, Larsson P, Larsson L. Inhalation of swine dust induces cytokine release in the upper and lower airways. Eur Respir J. 1997;10:381-7.

7. Sundblad BM, Larsson BM, Palmberg L, Larsson K. Exhaled nitric oxide and bronchial responsiveness in healthy subjects exposed to organic dust. Eur Respir J. 2002;20:426-31.

8. Palmberg L, Larsson BM, Malmberg P, Larsson K. Airway responses of healthy farmers and nonfarmers to exposure in a swine confinement building. Scand J Work Environ Health. 2002;28(4):256-63.

9. Larsson BM, Larsson K, Malmberg P, Palmberg L. Airways inflammation after exposure in a swine confinement building during cleaning procedure. Am J Ind Med. 2002;41:250-8.

10. Palmberg L, Larsson BM, Sundblad BM, Larsson K. Partial protection by respirators on airways responses following exposure in a swine house. Am J Ind Med. 2004;46:363-70.

11. Sundblad B-M, Sahlander K, Ek A, Kumlin M, Olsson M, Larsson $\mathrm{K}$, et al. Effect of respirators equipped with particle or particle-and-gas filters during exposure in a pig confinement building. Scand J Work Environ Health. 2006;32(2):145-53.

12. Pedersen B, Kai P. Rengøring af svinestalde [Cleaning of swine confinement buildings]. Meddelelse Landsudvalget for Svin 1998;376.

13. Larsson K. Rengöring av svinstall [Cleaning of swine confinement buildings]. Uppsala (Sweden): Institutet för jordbruks- och miljöteknik; 2000.

14. Sundblad B-M, von Schéele I, Palmberg L, Olsson M, Larsson K. Repeated exposure to organic material alters inflammatory and physiologic airway responses. Eur Respir J. 2009;34:80-88.

15. American Thoracic Society. Standardization of Spirometry, 1994 Update. Am J Respir Crit Care Med. 1995;152:1107-36.

16. Hedenström H, Malmberg P, Agarwal K. Reference values for lung function tests in females: regression equations 
with smoking variables. Bull Eur Physiopathol Respir $1985 ; 21: 551-7$.

17. Hedenström H, Malmberg P, Fridriksson HV. Reference values for lung function tests in men: regression equations with smoking variables. Ups J Med Sci. 1986;91:299-310.

18. Malmberg P, Larsson K, Thunberg S. Increased lung deposition and biological effect of methacholine by use of a drying device for bronchial provocation tests. Eur Respir J. 1991;4:890-8.

19. Chinn S. Methodology of bronchial responsiveness. Thorax. 1998;53:984-8.

20. American Thoracic Society. Recommendations for standardized procedures for the on-line and off-line measurement of exhaled lower respiratory nitric oxide and nasal nitric oxide in adults and children-1999 [official statement]. Am J Respir Crit Care Med. 1999;160:2104-117.

21. Zetterquist W, Pedroletti C, Lundberg JO, Alving K. Salivary contribution to exhaled nitric oxide. Eur Respir J. 1999;13(2):327-33.

22. Bascom R, Pipkorn U, Lichtenstein LM, Naclerio RM. The influx of inflammatory cells into nasal washings during the late response to antigen challenge: effect of systemic steroid pretreatment. Am Rev Respir Dis. 1988;138(2):406-12.

23. Larsson K, Tornling G, Gavhed D, Muller-Suur C, Palmberg L. Inhalation of cold air increases the number of inflammatory cells in the lungs in healthy subjects. Eur Respir J. 1998;12:825-30.

24. Larsson K, Eklund A, Hansson L-O, Isaksson BM, Malmberg PO. Swine dust causes intense airways inflammation in healthy subjects. Am J Respir Crit Care Med. 1994;150:973-77.

25. Strandberg K, Ek A, Palmberg L, Larsson K. Fluticasone and ibuprofen do not add to the effect of salmeterol on organic dust-induced airway inflammation and bronchial hyperresponsiveness. J Intern Med. 2008;264:83-94.

26. Charavaryamath C, Juneau V, Singh SS, Janardhan KS, Townsend H, Singh B. Role of Toll-like receptor 4 in lung inflammation following exposure to swine barn air. Exp Lung Res. 2008;34:19-35.

Received for publication: 11 June 2009 